\title{
RATIONALITY AND ITS OTHER
}

What I wish to do briefly is to outline a phenomenology of the other, in response to post-modern challenges to phenomenology and other forms of western rationality on that score. Is modern, westem rationality essentially opposed to the other, inevitably dominating her, excluding her, reducing her to sameness? If so, then a recourse to a post-modern, post-western form of rationality becomes necessary, whether one call that "genealogy" or "Denken" or "negative dialectic" or "deconstruction," to name a few of the more common alternatives.'

One way of testing such big claims and answering such big questions is to begin by thinking. "small," doing patient, phenomenological description of various forms of rationality as we experience them. In this way we are philosophizing in the spirit of Husserl, who warned of the dangers of a "philosophizing from on high" that, because it does not attend to the experience grounding fundamental concepts, goes astray. If we think, for example, that perceptual experience is fundamentally atomistic, then we will have Hume's problem of how to link these aspects perceptually or causally. If such an atomistic account can be shown phenomenologically to be inadequate, then Hume's problem dissolves. ${ }^{2}$

In the context of the debate between post-modernism and modernism, the danger is that of an "anti-philosophical philosophizing from on high" that, because it ignores how we experience rationality, does not do justice to the many different forms of rationality, some of which may be beneficent and open to

'Theodorc Adorno and Max Horkheimer, The Dialectics of Enlightenment, trans. John Cumming (New York: Seabury, 1972), pp. 3-42. Jacques Derrida, Of Grammatology, trans. Gayatari Chakrovorty Spivak (Baltimore: The Johns Hopkins University Press, 1974), pp. 3-73. Martin Heidegger, The Question Concerning Technology and Other Fssay, trans. William Lovitt (New York: Harper Row, 1977), pp. 3-35. Michcl Foucault, Discipline and Punish: The Birth of the Prison, trans. Alan Sheridan (New York: Vintage, 1979).

${ }^{2}$ Edmund Husserl, Formal and Transcendental Logic, trans. Dorion Caims (The Hague: Martinus Nijhoff, 1969), p. 278. 
experience rationality, does not do justice to the many different forms of rationality, some of which may be beneficent and open to otherness. We can get into fun-filled debates carrying far into the night when someone claims that "all judgments are police actions" or "modern rationality is essentially dominating" or "modern rationality is essentially closed to otherness," but the discussion is misconceived or misguided and derailed because it ignores the fundamental descriptive disclosure of rationality as we experience it. In this respect Husserl's descriptive approach to experience remains an indispensable approach to a philosophical discourse that wishes to get somewhere and not just twist in the wind. Philosophical discourse also has legitimate hermeneutical, critical, and explanatory moments, but these inevitably miss their target unless they are descriptively grounded. $^{3}$

Our suspicions on these scores begin to be confirmed when we reflect initially on the supposed dichotomy between consciousness as an immediate form of rationality or forms of philosophy such as phenomenology based on description of conscious experience and the other person. Either the claim about the dichotomy between consciousness and the existing other is stated with evidence or it is not. If the claim is made with evidence, then such evidence implies a relationship to a conscious knower. If the claim is made without evidence, then what is arbitrarily asserted can be rationally questioned or denied.

What such brief dialectical reflection on otherness shows is the necessity of its being related to a conscious knower. What phenomenological description shows is how such a relation occurs. I propose to begin this task by reflecting phenomenologically on a conversation, describing in a relatively presuppositionless way what goes on in a conversation and then, basing ourselves on such a description, articulating what is essential to that experience. Let us imagine two adults, Joan and John, each of whom Socratically and philosophically is trying to arrive at the truth. Let us imagine Joan initially arguing $A$ and

3James L. Marsh, Post-Cartesiun Meditations (New York: Fordham University Press, 1988), pp. 25457; hereafter referred to as PCM. 
John, disagreeing, arguing not-A. In the course of the conversation, John comes to agree fully and rationally with Joan. Such agreement, however, because it is not coerced and rational, does not imply any violence to John's otherness. The same would be true if he convinced Joan to see the error of her ways. "John, you are right." After the conversation, they join hands and go out for a drink. No one's otherness has been violated.

Another possibility, of course, is that John and Joan boh modify their positions so that at the end of the conversation they both agree, but each position is a blend of $A$ and not $A$. Consensus is present again, but where is the violation of otherness? Another possibility is that each maintains their respective position, but this position is qualified ornuanced in respect to the other person's. Here again it seems to me that there is no violation of otherness or reduction of otherness to sameness. Each retains their difference in responding to the other. Another possibility is that both remain exactly where they were at the beginning of the conversation, $A$ andnot-A.

We have, then, four positive possibilities in a noralienated conversation that does justice to otherness: one person agreeing freely and rationally, both persons moving to a third position, each person modifying their position in relation to the other's, and both persons remaining where they were at the beginning of the conversation. Each of the positions involves a blend of identity and difference, identity being more identified in the initial and difference more emphasized in the final instances listed above. Nonetheless difference is present even in total agreement insofar as the agreement is not coerced or manipulated and the persons remain spatially and existentially distinct. John is here with his own particular life history, and Joan over there. Identity is present even in total disagreement insofar as the positions have preserved themselves in a conversation with shared traditions, goals, and presuppositions. Joan and John come out of a common philosophical tradition, are aiming at the truth, and share presuppositions such as that concerning the value of an uncoerced consensus.

Now it is obvious that there are also negative possibilites. A person can try to force her views on the other, manipulate him, 
or coerce him into agreement. Here is an obvious, illegitimate reduction to sameness, a lack of attention to or valuing of difference, and domination. What is also true, however, is that such abuses can be criticized within the context of the conversation itself. "You are not listening to me" or "you are being dogmatic" or "you are being contentious." Such behavior, we could say, violates the basic thrust of the conversation itself toward a rational, free agreement respectful of difference and listening to the other. Such manipulation or coercion or domination is not experienced as rational but as irrational or at least as inadequately rational. A less adequate form of rationality is criticized in the light of and in the context of a more adequate, comprehensive form of rationality.

Nonetheless further objections to my account can occur. Does not rationality of the kind I am defending claim to totally know or control the other? Once again close phenomenological description reveals that this is not so. Even with regard to knowing things, we could say that we know things from a point of view perspectivally. I can see the front side of the table, but not the back side; I am aware of the top of the book but not the bottom. In addition to such knowledge of things, persons through profiles, knowledge of persons adds a dimension of interiority rooted in a reflectively and freely lived life history. The person can reveal herself to me or withhold herself, tell me the truth or lie, dissimulate or be open. If I arrive at some knowledge of her now, also present is a pro-thematic context, historical and personal and reflective, that I dimly sense but have not fully plumbed. The claim to exhaustively know the other, therefore, reveals itself to be not an essential expression of consciousness or rationality, but rather a violation of them, a hubristic attempt to transcend the eidetic laws governing knowledge of the other.

But is not the attempt in conversation to thematize the other or objectify the other, an illegitimate reduction to sameness insofar as this thematizing leaves out the experience of the other as other, as he experiences himself in relation to me? In one sense, of course, this claim is true; no immediate experience as

${ }^{4}$ Ibid., pp. 143-57. 
immediate is fully captured by any objectification or thematization of it; my experience of "green" is not fully captured by linguistic references to it as green or my descriptions of it. Nonetheless one thematization can be appropriate or true in a way that another cannot. I can capture truly the meaning of "green" when I adequately describe it; I do not capture truly the meaning of "green" when I misdescribe it as "red."

Similarly I can capture truly the meaning of another person in the ways appropriate to her behavior and being as a person: embodied, historical, intersubjective, rational, and free. I misdescribe or mistreat her when I describe her or treat her like a thing with no interiority. Treating a woman like a sex object is an example of such treatment.

Just as we need to distinguish between immediate experience (understanding, of course, that no experience is strictly or purely immediate but is mediated by language and meaning and universality) and thematic meaning and between untrue and true thematizations, so also we can distinguish between alienating and non-alienating thematizations. When I say to you without cause, "you are an idiot," I am insulting you inappropriately. When I say to you, "You were insightful and helpful in this argument," that statement is not alienating, nor do you experience it as such. Rather, you experience it as positively self-enhancing, an expression of my good will toward you.

Untrue and alienating thematizing can occur, but it is not inevitable nor is it to be identified with thematization as such, nor does it deny that true thematizing can reveal the meaning or sense of the other. Nor is it the case that in a conversation we are always trying to thematize each other in a propositional way. Rather what can occur and does occur is that you and I are concerned with the theme of the conversation, for example the meaning of being, the injustice of capitalism, or the validity of the late Picasso's art. I am aware of you perceptually as a participant in the conversation but our main focus is the question being pursued in the conversation.

Nor is it true, whether or not we are concerned dominantly with a theme or with each other, that we are always dealing constantly with truth claims. Rather the moral rightness or 
wrongness of a course of action or expressiveness can be the main point: "I love you." Consciousness and rationality, though they are thematic in a pro-thematic context, are not always thematic in the same way, they are not always propositionally thematic, nor are they concerned with propositional truth. An account that makes the propositional and constative the whole story is a caricature. ${ }^{5}$

Am I illegitimately presupposing consensus in my description of such a conversation? In one sense I am not, for I have already admitted that disagreement is a possible outcome of a conversation. In another sense, to the extent that the conversation is oriented to truth, I am presupposing the value of consensus, but not illegitimately. Rather I am claiming that a true, eidetic description of the conversation reveals it to be governed by the value of consensus. For true judgments to be made, all of the relevant question have to be answered or resolved; disagreement implies that some questions are unresolved. Truth implies universality noematically and noetically; disagreement implies universality has not been achieved. Not everyone agrees that the categorical imperative is true, that capitalism is unjust, or that the meaning of Being is to move from concealment to unconcealment.

All of this is not to deny that conversations can occur in which one or more of the persons involved are not aiming at truth or consensus; in that respect they are insincere. But in such a case they trade on the value of consensual truth; otherwise the conversation could not go on. Conversations can also occur that are ironic, playful, aesthetic, emphasizing difference more than agreement. In that case there is a tacit or explicit "agreement to disagree." Consensus is presupposed as the basis of the conversation, without which it could not occur; and as a norm or goal, which it aims to attain or can be contrasted with playfully

5If the alert reader has detected Habermasian overtones in some of this discussion, she is correct. Even though I am not formally drawing on or using Habermas here, he seems to have undoubted insights into communicative praxis using his own kind of descriptive analysis. See his The Theory of Communicative Action. I: Reason and the Rationalization of Society, trans. Thomas McCarthy (Boston: Beacon Press, 1984), pp. 1-42. 
and aesthetically. Consensus also operates in the process of the conversation itself, and each person attempts to accurately and adequately understand the other, to arrive at new shared insights, and critically and sympathetically test judgments. As presupposition, norm governing the process, and goal, consensus can be violated, but then the conversation is a deficient conversation.

Finally one could object to my account inspired to some extent by a Husserlian methodology that it gives importance to an active consciousness and not enough to the initiative of the other person. But once again here, either that initiative is genuinely experienced and known or it is not. If the former, then the initiative implies reference to a conscious knower. If the latter, what is arbitrarily asserted can be rationally questioned or denied. If the ethical call of the other is genuinely heard, then does not such hearing imply conscious experience that does the hearing and can be described? Such a description implies attention to the passivity and receptivity of conscious experience, which I have already articulated in my description of a conversation. The conversation is a give-and-take in which I respond to the other and she to me, I take the initiative and then she does I listen to her and she to me. ${ }^{6}$

Husserl, I think, already recognized this passivity and receptivity in conscious experience in his phenomenologies of perception and the other person. The die when I throw it may turn up a six or a five, but whether it does or notis not up to me. The person to whom I am speaking may agree with me or not, but whether she does or not is not up to me. To the extent that the post-modern or Levinasian critique of phenomenology is based upon a conception of consciousness as purely active, this critique is based upon a caricature?

GEmmanuel Levinas, Totality and Infinity, trans. Alphonso Lingis (Pittsburgh: Duquesne University Press, 1969), pp. 187-253. I do not mean to imply here that Levinas is a post-modernist, but his arguments can be used and have been used in a post-modem context.

7Edmund Husserl, Cartesian Meditutions, trans. Dorion Caims (The Hague: Martinus Nijhoff, 1960), pp. 41-43, 106-20. 
Here there is a conditioned, a condition, and a link between the two. The conditioned is the virtually conditioned judgment, "I know other persons." The judgment is a virtually unconditioned judgment because it is a judgment that must have its conditions fulfilled, and such fulfillment is not inevitable or necessary. The conditioned is simply the conclusion, and the link between the conditioned and the condition is a materially analytic claim defining what other persons are. A materially, as opposed to formally, analytic claim is true not because denying it would violate the principle of contradiction, but because the claim arises from reflection on experience.

To know others is initially perceiving them in all three senses of that term, experience, understanding, and judgment. I physically experience the person, I understand her as a person, not a thing, and as an individual person, Joan; and I judge that this is indeed a person, Joan, to whom I am speaking. Joan is known as a "person" to the extent that she is cognitive, in the sense of being able to experience, understand, and judge; and volitional, in the sense of being able to choose, commit herself, choose a course of action, and love. Again the other person is not a noumenal spirit in some noetic heaven, but one essentially related to her body and manifesting herself through her own embodied behavior, in and through a body perceived as different from mine. ${ }^{9}$

The fulfillment of the conditions is given in phenomenological reflection upon conscious experience. Here, as in the discussion of perceptual experience, it is not a matter of inference from private states of consciousness but explicating evidence that is already present implicitly. Consciousness is not locked up inside itself confronting only its own representations but is intentionally present to the world. Such an explication of evidence has four steps: the evidence forotherness in general, the evidence for specific kinds of otherness, the evidence for the otherness of human persons, and a richer, stronger kind of

${ }^{8}$ See my PCM for an initial development of this argument, pp. 12831. For the distinction between materially and formally analytic,see $P C M$, p. 65 .

9/hid.,pp. 45-72. 
but is intentionally present to the world. Such an explication of evidence has four steps: the evidence for otherness in general, the evidence for specific kinds of otherness, the evidence for the otherness of human persons, and a richer, stronger kind of objectivity.

The evidence for otherness I have already articulated elsewhere. In my discussion of perception, I discovered five modes of perceptual objectivity: A) the unity of the thing in contrast to many perceptual acts; B) the presence of the thing as detachable, there, and thematic, in contrast to my own lived body as inseparable from me, "here," implicit; C) the presence of the thing as perspectival and subject to only a presumptive synthesis, in contrast to the massive, mute, non-perspectival presence of the perceiving body; D) the independent content of the thing in acts proceeding from me as perceiver; E) the thing as gestalt emerging from a background, in contrast with the living gestalt of my body, the subjective background from which my act of perception proceeds. Thus I see the chair over "there" in contrast to my own lived body "here," I can move around it touching it and viewing it, I perceive it as a whole in contrast to the background of the room, the chair is a unity achieved through many individual acts of perceiving, and it has a content of color and shape and texture that is independent of and not reducible to my acts of perceiving. My lived body is not distinct from me as an instrument, but is my lived presence in the world. I "am" my body. ${ }^{10}$

We are in a world, moreover, in which different kinds of otherness manifest themselves. Rocks, trees, and dogs are all objects of my consciousness and, therefore, independent of me, but rocks, trees, and dogs are specifically different from one another--they have a different kind of presence. I can grow a tree but not a rock; I can train Fido to hunt ducks, but I cannot so train a tree. My interaction with rocks, trees, and dogs rests on manifested, verifiable properties and activities in these objects, such as the hardness of the rock, the growing of the plant, and the running of the dog. Plants and dogs reveal themselves to me as

10 lbid., pp. 45-54. 
different forms of life, self-moving, growing, self-maintaining organisms. Dogs, moreover, can move and sense, whereas plants cannot do so. Here are forms of behavior manifesting themselves in bodies that are experienced as other, as having the five aspects of perceptual objectivity described above.

It is in the context of multiple kinds of otherness that I experience other persons. For what becomes clear is that there is another kind of embodied life with a different kind of presence. It not only grows, senses, and moves, but talks, gestures, and paints pictures. I can talk at Fido, but I can talk with this other kind of life, which can also talk and disagree with me in a conversation. I can put my plants anywhere I wish in my apartment with no protest from them, but these other beings can resist me, disobey, refuse to go or be where I wish. I can train and indoctrinate Fido, but these other strange beings can resist being trained and indoctrinated and express their indignation in being so treated.

There is a sense, therefore, in which I feel and sense a community with these other beings; they reveal themselves as "like me." We should not, however, take this "like me" quality in an explicit, inferential sense. Rather my lived body implicitly resonates with the lived body of the other in a way I do not with trees or dogs. With other persons I spontaneously anticipate a certain kind of response that answers to and corresponds with my experienced behavior: anger when I am angry, love when I am loving, joy when I am joyful. When I ask a question in conversation, I expect to get an answer and am disappointed when I do not. When I make a proposal, I expect agreement or disagreement. Such responses I do not demand or expect from my plant or dog. They can respond to me only in a limited, relatively exterior way. The full riches of my interiority are closed to them; with the human other, however, there is no limit to self-revelation.

In his behavior, therefore, the other manifests himself to me as an expressive consciousness in his language, gestures, and actions. As I perceive the gestalt of a table in a room immediately, so I can read anger in the face of the other as he perceives the wreck I have made of his car. As I can enlighten 
and criticize the other through what I say, do, or create, he can enlighten and criticize me. In contrast to my relationship to things, plants, and animals, the other can relate to $\mathrm{me}$ in a conversation in a fully reciprocal way. As I can lie, resist, or withhold myself from the other, so he can do the same with me. Indeed the ability of the other deliberately to deceive me or hide something from me or resist me, rather than bring evidence against his existence, is evidence for his existence. Through such behavior the interiority of the other manifests itself and reveals him as specifically different from a rock, plant, or dog. I can deceive myself and have mistaken perceptions about all of these objects and about the other person as well. But only he can deceive me about himself, i.e., lie to me or hide himself from me. I can dominate my dog, order it around, and treat it in a cruel way, but among the objects in my experience only the other can alienate me, dominate me, "look" at me in Sartre's sense. Such a negative look is not necessary nor inevitable. Indeed, as I have shown, non-alienating, self-enhancing conversation can occur, but the possibility and actuality of the alienating look is certainly one important bit of evidence for the meaning and reality of the other. ${ }^{11}$

As I know all objects of my perceiving consciousness, so I know the other only in a presumptive way. I can look at a department store mannequin and think it is a person; I can look into the distance and mistake one person for another. Just as mistaken perceptions about particular objects presuppose the validity of perception in general (I can know the stick in the water was not bent only in the light of a subsequent true perception), so mistaken perceptions of the other presuppose the sense and existence of the other. I can know only in the light of a subsequently true perception that the other has deceived me, and I can know only in the light of past behavior indicating such interiority that the other is capable of deceiving me.

With the presence of the other we have objectivity in the full sense of the word. Objectivity means not simply what I

11 Jean-Paul Sartre, Being and Nothingness, trans. Hazel Barnes (New York: Citadel, 1964), pp. 228-78. 
experience, understand, or judge for myself, but what is intersubjectively true. The perceived thing is present to me as something that not only I but the other perceives, and her perceptions can correct, complement, or deepen mine. An objective claim in science, mathematics, or philosophy is one that is universally true for all persons. Here we encounter the basis for consensus as a regulative ideal in conversation.

\section{Conclusion}

Significant implications emerge from this account. The first is that if my phenomenological account of a conversation with the other is true, then we can affirm as well a second order theoretical openness to otherness that does not close it off. Not only is consciousness and conscious rationality open to its other in a first order way, but also at least one form of modernist rationality, phenomenology, is open to its other. If so, then the general indictment of modernist rationality as essentially closed to otherness falls to the ground.

A second implication is that abuses of rationality do occur: illegitimate reduction to sameness, assimilation, domination, exploitation. But we can only criticize those from the perspective of a more comprehensive, deeper kind of rationality. Here another dilemma emerges: either the critique of such abuses is made with evidence or it is not. If the critique is made with evidence in such a way that we accept it as true, then a more fundamental, comprehensive form of rationality is at least tacitly presupposed. Otherwise we would not accept the critique as evidential and true. If, on the other hand, the critique is not made with evidence, what is arbitrarily asserted can be rationally questioned or denied. Here the deeper, more comprehensive form of rationality is the conversation on a first order level, in relation to which abuses can be criticized; and descriptive, eidetic phenomenology on the second order level, in relation to which one-sided, arbitrary accounts of experience can be criticized.

Next, we have just taken a first step in discussing the question of the relationship between rationality and its other. 
We have been doing patient phenomenological description trying to avoid a "philosophizing" or "anti-philosophizing from on high." If I am correct, there is no essential gap between rationality and its other, rather an essential link and connection. Reason in general and modernist rationality in particular is being most rational when it is most fully open to its other, least rational when it is most closed.

Finally, even though I have taken a first step, fruitful hypotheses for future research suggest themselves concerning hermeneutical, ethical, and political dimensions of the relationship between rationality and its other. If consciousness as lived is already open to its other, if phenomenology can criticize inadequate or dominating ways of relating to the other, then post-modern rejection or transcendence or overcoming of such rationality seems implausible. Rather more fruitful and plausible would seem to be a dialectical "yes" and "no" to modernity and its pathologies of domination, in which less adequate forms of rationality are evaluated and criticized by more adequate and non-dominating forms. Such is the hermeneutical and political, as not opposed to but flowing from, depending on, and going beyond, the descriptively phenomenological argument that I have made given here. ${ }^{12}$

Fordham Untversity

JAMES L. MARSH

$12 P C M$, pp. $200-58$. 